\title{
Scientific and Medical Research Involvement amongst High School Students and Career Exploration Initiatives: A Scoping Review
}

\author{
Abramo Aziz Rizk, Mohid Farooqi, John Sarga, Mahmoud Al-Izzi, Monica Elzawy, Ahmed Al-Izzi, \\ Abanoub Aziz Rizk \\ Bishop P. F. Reding Catholic Secondary School, 1120 Main St E, Milton, Ontario, L9T 6HT, CANADA; abramorizk@gmail.com.
}

\begin{abstract}
Involvement by high school students in scientific inquiry expands experiences and enriches education. Research experiences can be utilized in high school education in an attempt to improve students' critical thinking skills through introducing the following interventions: science fairs, in-class experimentations, and research papers. The aim of this study was to collect current data and discuss the efficacy, drawbacks, and future goals for these interventions. The objective of this study was to develop an outline of how research might be introduced into the high school curriculum and present the strengths as well as limitations of such initiatives. This review was written in a scoping review format using the five stages of the proposed approach by Arksey and O'Malley and advanced by Levac, Colquhoun, and O'Brien. PubMed and Gale Academic OneFile databases were used to search for articles related to high school students engaging in research. While each method of implementation of research into the high school curriculum has its strengths and limitations, they can be used in conjunction to complement each other. Implementing research into the curriculum may improve education at the high school level if it is incorporated correctly. Additionally, providing more opportunities for high school students to get involved in research may help guide interested students toward a suitable career path and may even spark new interests in some students.

KEYWORDS: High school; Students; Curriculum; Education; Research; Scientific inquiry; STEM.
\end{abstract}

\section{Introduction}

Research, which is the act of inferring new ideas based on past knowledge and investigating the truth of those ideas using observations, is an important aspect of science that allows for the evolution of human knowledge. ${ }^{1}$ A study suggested that high school students' performance in science education has been on a downward trend, suggesting that the importance of science is being diminished over time. ${ }^{1}$ Teaching students how to conduct research may have the potential to improve many basic skills one might need in life, such as critical thinking skills and the ability to consult multiple sources before making conclusions on a subject.

In Canada, high school is a fundamental part of the education of students. It provides a basis of knowledge required to enter the workforce or specialize that knowledge further through higher education. Currently, in the general science curriculum, science is taught in a way that "does not stimulate application-based approach of course delivery" or the ability to make conclusions by oneself. ${ }^{2}$ Instead it emphasizes memorization over application of material. ${ }^{2}$ It has been suggested that this can cause students to lack critical thinking skills and be unable to create causal links. ${ }^{2}$ To develop students' abilities in science, research can be used to show them methods by which ideas are discovered, thereby developing their abilities to think critically.

There are numerous ways through which research can be introduced to high school students including the following: science fairs, in-class experimentations, and adding research papers into the science curriculum. Science fairs are science projects that groups, or individuals can work on which will be evaluated by a group of judges. Since there are both competitive and non-competitive science fairs, it is a good way to inspire interest in science education. In-class experimentation is a method that can provide students with experience in the science field by providing opportunities to preform experiments firsthand. Lastly, research papers can be implemented to help students critically think about scientific topics.

There are currently several uncertainties in the area of research in high school education. Firstly, it is unknown which method of research incorporation into the high school curriculum introduces the greatest benefits while also minimizing the drawbacks for the students and faculty. Additionally, the exact effectiveness of each method is also unknown as there is a lack of quantitative studies analyzing the effectiveness of each method. While there is a lack of quantitative assessment, expert opinions have been compiled in this paper. The final area of concern is the gap between successful and struggling students which may be created by introducing a richer curriculum. Given the large amount of uncertainty, a more collaborative effort, and a summary of what has been previously studied is required. It is beneficial to know what the research shows so that new principals, directors, and departments of education will be better equipped to make more informed decisions for future steps.

Early exposure to STEM (science, technology, engineering, mathematics) at the high school level is important as it helps young students direct their steps toward a suitable and fulfilling career. Additionally, providing high school students with 
the opportunity to gain experience in the healthcare system is another method by which students can discover their interests. In this way, students can receive a holistic view of the roles and responsibilities associated with various healthcare careers before deciding to pursue higher education in the medical field.

This study aims to collect the current data and discuss the efficacy, drawbacks, and future goals for each of these interventions while also posing an outline of how research might be introduced into the high school curriculum and presenting the strengths and limitations of such initiatives.

\section{- Methods}

This study was written in a scoping review format, which is predominantly used when the topic in discussion has not been well-researched. Scoping reviews are used to organize literature, unlike systematic reviews which address a single question. There are various reasons why scoping reviews are conducted, including covering key concepts, and analyzing and identifying knowledge gaps. The five stages of the proposed approach by Arksey and O'Malley and advanced by Levac, Colquhoun, and O'Brien was used, which is considered a methodologically rigorous scoping review. These five stages are as follows: (1) finding research questions, (2) searching for relevant literature, (3) filtering studies that do not fit the inclusion criteria, (4) inputting the data in a chart, and (5) summarizing, acquiring, and reporting the results.

This literature review searched through various databases to locate studies that documented methods of engaging secondary students in research activities. PubMed and Gale Academic OneFile were searched for articles that have been published between the years 2003 to 2020 .

Inclusion criteria for the studies were: (1) the participants had to include high school students and (2) the students were conducting any form of research. Any studies with students in higher education (e.g., undergraduate studies) and articles that were not written in English were excluded. This study searched articles related to the keywords below using the following search criteria: adolescent [MESH and keyword search], students [MESH and keyword search], research personnel [MESH], laboratory personnel [MESH], high school [keyword search], secondary school [keyword search], middle school [keyword search] AND research [MESH and keyword search], science [MESH and keyword search], Proof of Concept Study [MESH], Problem Based Learning [MESH], experiment [keyword search], science fair [keyword search], experimental [keyword search], STEM [keyword search], informal learning environment [keyword search], hands-on [keyword search].

\section{Results}

Eleven studies fit the inclusion criteria described above. Three studies analyzed the effectiveness of science fairs in promoting interest and skill development in research and experimentation. These studies used student opinions regarding their experiences to draw conclusions about the benefits and drawbacks of science fairs, and whether or not they should be mandatory. In addition, five studies focused on providing students with real-world research experience. They accomplished this by giving the students a chance to work with three studies focused on unique methods through which high school students can conduct research inside the classroom.

Table 1: Review of data collected on effects of research implementation in the high school curriculum.

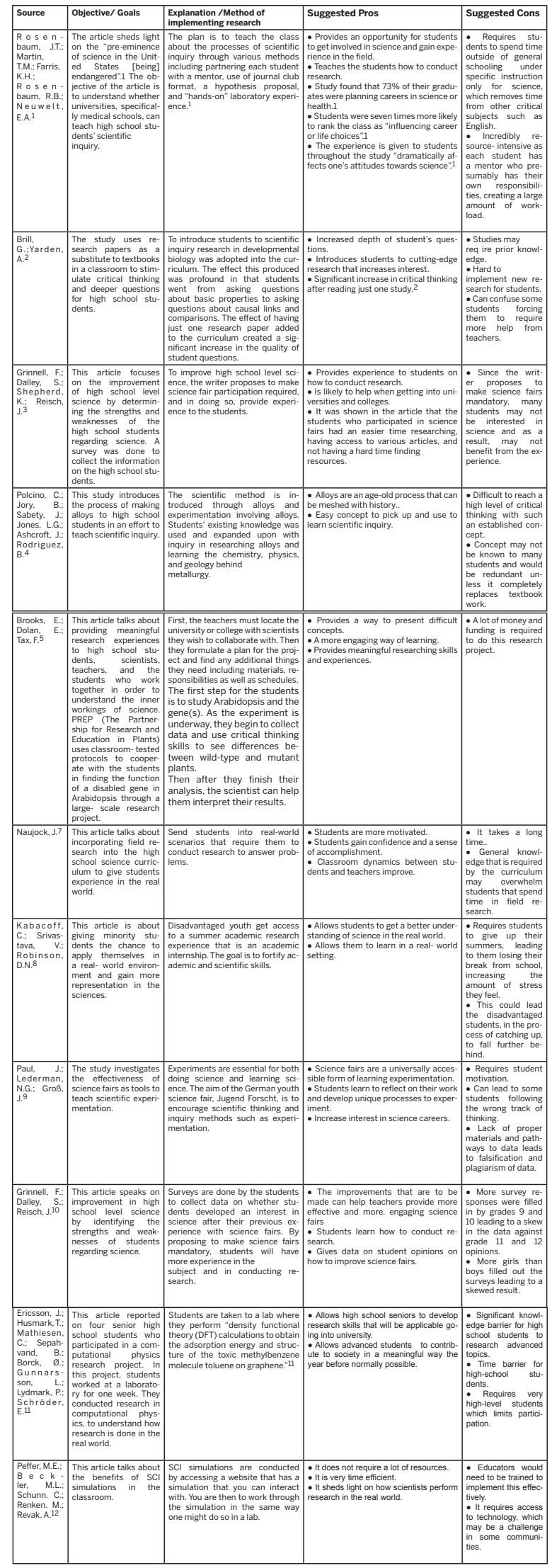




\section{Discussion}

In this review paper, the need for the inclusion of research in the high school curriculum was identified and several methods to implement research were provided. To determine effective methods for high school students to take part in research, a scoping review was conducted. Three methods were preeminent in providing an avenue to conduct research including science fairs, in-class experimentation, and incorporating research papers into the science curriculum.

One method of engaging high school students in research is through science fairs. During a science fair, students are asked to research and develop an idea that they present to a group of judges. If the science fair is competitive, the judges will evaluate all of the projects and subsequently crown a winner. If the science fair is non-competitive, the judges will give each contestant feedback on their ideas and areas of improvement. Additionally, they will not declare a winner. Each type of science fair has its benefits and drawbacks. Competitive science fairs are shown to work better with students who have already developed an interest in science before competing. This is because these students have a desire to compete and win the competition. This type of science fair generally does not interest students who do not have a passion for science. A study was done which gathered student opinions on science fairs. In this study, one student mentioned that when they were forced to compete, some students could have an advantage as they might potentially have family connections to a scientist or have been exposed to gathering research from academic studies. ${ }^{3}$ This leaves the students without these aforementioned advantages feeling that the science fair is futile due to their inability in competing with other students who may have many more resources than them at their disposal. ${ }^{3}$ In conclusion, this type of science fair is well suited for students who already display interest in the subject of sciences, lending them valuable background experience in research that could be used beyond secondary school education. However, it can be unwise to force all students to compete in science fairs, since many students who either do not want to win or do not think they can win can feel alienated from the competition.

On the contrary, non-competitive science fairs generally appeal to a wider range of students. They can allow students who have a passion for science to explore their areas of interest and present them to the judges to get feedback on their ideas. However, it does not take advantage of some students' competitive nature in the same way that a competitive science fair might. It also allows students who do not have an interest in STEM (science, technology, engineering, mathematics) to select a topic that they think they would be interested in and develop a project based on that idea. As a result, these students may develop a passion for a new topic while also providing an opportunity to present it to the judges to get feedback on their ideas. Non-competitive science fairs might not present the same challenge that a competition traditionally would, but they can still be considered an opportunity to improve student skills. Both methods of implementing science fairs types of students. A common issue between each of the methods is that they can take an extensive amount of time and resources to implement. The current Ontario curriculum demands students learn a certain amount of core, foundational knowledge to pass the exam stages and acquire a high school diploma. In other words, introducing science fairs into the secondary education module without altering the time spent in other areas would increase the workload on students and render them feeling overwhelmed.

Another method of introducing research to high school students is through in-class experimentation and explanation of ideas. For example, in order for students to learn about alloys, they would be given the methods and materials to create different alloys, then followed by being tasked with answering questions about the process, and finally formulate conclusions as well as potential causal links.

Consequently, students could be able to conduct research and utilize the scientific method in a simpler, friendlier, and more guided manner. This method can be applied in a way to demonstrate the process by which scientific ideas in the curriculum were discovered. Although in-class experimentation has many benefits, there are still limitations as to what it can accomplish. Primarily, most of the concepts introduced through the experiments are well-established concepts. For instance, one of the studies reported on teaching high school students about creating alloys, a process that has been carried out for hundreds of years. ${ }^{4}$ As a result, it is possible that levels of critical thinking are lessened. Another challenge is the high financial demand for implementation. This includes difficulties in covering the costs of the materials as well as the costs associated with training teachers.

The final method is to use research papers to showcase to high school students how to appropriately form causal links and critically think about scientific topics. Before being exposed to the way scientists think, high school students "tend to ask only questions of the properties category." 2 To show students what type of questions to ask and how research is conducted, they can read articles and make their own hypotheses while following the research paper introduced to them. This can allow students to ask deeply meaningful questions, form creatively enhanced links and out-of-the-box style of thinking. While this method requires significant alterations to Ontario's high school curriculum and serious effort from teachers to implement, it is flexible in terms of the level of difficulty. ${ }^{2}$ Implementing research papers may also be one of the easiest for teachers to incorporate in high schools but could be one of the hardest for students to grasp and understand. Even though it requires no added infrastructure or materials, students will become required to demonstrate effort into reading and understanding advanced educational studies. It is important to note that this method is the most well-documented in terms of results as it has statistical evidence. A study was conducted by Brill and Yarden ${ }^{2,5}$ in which secondary students were tasked to create questions and answers. In advance of being introduced to any of the learning, $94 \%$ of the students asked declarative questions; however, after they were exposed to a research paper, $21 \%$ of the students made causal relationships. ${ }^{2}$ The substantial change in the types of questions asked after reviewing only 
one research paper demonstrates the efficacy of this method of teaching students about science. ${ }^{2}$ Notably, this method of implementation can deliver promising benefits, including the following: increased depth of questions, ease of implementation, and an enhanced understanding of the scientific method for students. Due to the lack of studies on this topic, the effects that implementing research papers will have on struggling students are not yet understood and no sufficient analysis can be inferred on individual students. ${ }^{2}$ One possible way to implement this method into Ontario's high school curriculum is to introduce a research paper in every unit and guide students through the procedure of learning research work in detail. While reading the papers, students are shown how researchers reach their conclusions and establish facts.

\section{Strengths and Limitations:}

A strength of the study includes how the study identifies three ways of integrating research into the school environment, as well as providing the positives and negatives of each method. Identifying this allows the study to be more impartial and less biased. The limitations of the study are that there is a limited volume of academic literature, from which statistical evidence is even more sparse due to which a significant conclusion is hard to reach. Even though there is a limited volume of literature on this topic, significant pros and cons could not be included. It is recommended that future studies focus on the interventions discussed in this review; science fairs, in-class experimentation, and research papers in hopes of providing more concrete statistical evidence to support proper implementation of these interventions. Another limitation of this study is that the criteria of the searched articles may have excluded relevant articles and journals. Furthermore, exploring more education systems outside of the North American countries can help to analyze different methods of implementing research in the high school curriculum.

\section{Future Steps:}

To ensure the success of the interventions outlined in this paper, multiple steps can be taken. Firstly, additional studies can be carried out to analyze the different methods of research, specifically the impacts of the methods on individual students. Through conducting further research studies, the statistical efficacy of each proposed method will be made clear. Secondly, through the use of surveys, gathering the opinions of students who have participated in the trials for the interventions will be essential in applying for these programs on a large scale. This will allow students to offer advice on how to improve the programs and limit their drawbacks. Through these surveys, the curriculum can be modified to accommodate students. Lastly, studies can be conducted to determine how research may be implemented into the curriculum while ensuring students will not be overwhelmed by their workload. It is important to manage the load on students to make sure the gap between successful and struggling students is not increased, leading to an unfair working environment that is unrewarding for struggling students.

\section{- Conclusion}

There are many promising methods that high schools can employ to engage students in the process of research. Each method has its limitations and benefits, which is why implementing multiple methods can help compensate for the weaknesses of each method. Firstly, introducing research to high school students through research papers would be very effective as an introduction because there would be minimal changes to the infrastructure of the school. In addition, exposing students to how experiments are carried out can help them grasp more complicated forms of research. The students who are interested in science can sign up for an optional science fair in which they can gain experience in individually conducting research. The effectiveness of implementing research is corroborated by the consensus of all the studies discussed in this review, that it is beneficial for students. Thus, it can be concluded that integrating research into the high school curriculum can be an important step to improving the level of education in high schools

\section{Acknowledgements}

We would like to thank our mentors and supervisors: Abanoub Aziz Rizk, Ahmed Al-Izzi, and Monica Elzawy for catering to our requisites through their knowledge and experience. Furthermore, we appreciate the help and guidance from our senior post-secondary team bestowed in the success of this project. Albeit no funding was provided, we are truly grateful for having the opportunity to conduct this research project.

\section{References}

1. Rosenbaum, J.T.; Martin, T.M.; Farris, K.H.; Rosenbaum, R.B; Neuwelt, E.A. Can Medical Schools Teach High School Students to Be Scientists? Federation of American Societies for Experimental Biology Journal 2007,21 (9), 1954-1957.

2. Brill, G.; Yarden, A. Learning Biology Through Research Papers: A Stimulus for Question- Asking by High-School Students. Journal of Cell Biology Education 2003,2 (4), 266-274.

3. Grinnell, F.; Dalley, S.; Shepherd, K.; Reisch, J. High School Science Fair: Student Opinions Regarding Whether Participation Should Be Required or Optional and Why. Public Library of Science one 2018,13 (8), 1-16.

4. Polcino, C.; Jory, B.; Sabety, J., Jones, L.G.; Ashcroft, J.; Rodriguez, B. Advancing Alloys: Bringing Solid Mixtures to The High School Classroom. The Science Teacher Journal 2020,87 (7), 40-49.

5. Brooks, E.; Dolan, E.; Tax, F. Partnership for Research and Education in Plants (PREP): Involving High School Students in Authentic Research in Collaboration with Scientists. The American Biology Teacher 2011,73 (3),137-142.

6. Muncan, B.; Majumder, N.; Tudose, N. From High School to Hospital: How Early Exposure to Healthcare Affects Adolescent Career Ideas. International Journal of Medical Education 2016, 7, 370-371.

7. Naujock, J. Incorporating True Research Opportunities into High School Curriculum: A Research and Design Course. School Science and Mathematics 2009,109 (7),369-370.

8. Kabacoff, C.; Srivastava, V.; Robinson, D.N. A Summer Academic Research Experience for Disadvantaged Youth. Cell Biology Education A Journal of Life Science Education 2013,12 (3), 410418.

9. Paul, J.; Lederman, N.G.; Groß, J. Learning Experimentation Through Science Fairs. International Journal of Science Education 2016,38 (15), 2367-87. 
10.Grinnell, F.; Dalley, S.; Reisch, J. High School Science Fair: Positive and Negative Outcomes. Public Library of Science one 2020,15 (2), 1-17.

11.Ericsson, J.; Husmark, T.; Mathiesen, C.; Sepahvand, B.; Borck, Ø.; Gunnarsson, L.; Lydmark, P.; Schröder, E. Involving High School Students in Computational Physics University Research: Theory Calculations of Toluene Adsorbed on Graphene. Public Library of Science one 2016,11 (8), 1-12.

12.Peffer, M.E.; Beckler, M.L.; Schunn, C.; Renken, M.; Revak, A. Science Classroom Inquiry (SCI) Simulations: A Novel Method to Scaffold Science Learning. Public Library of Science one 2015,10 (3), 1-14.

\section{- Authors}

Abramo Aziz Rizk was born in Turin, Italy on the 12th of January 2005. He is a junior student at Bishop Reding Catholic Secondary School and is currently in the AP program. Abramo was also a recipient of the science and math award in grade 9.

Mohid Farooqi is a sophomore at Bishop Reding Catholic Secondary School. He has an interest in many fields including physics and neurology. Some of his accolades include high placement in Waterloo math competitions. He has ambitions to create change globally and hopes to do so through academics.

John Sarga was born in Egypt on May 28, 2004. John is a junior taking the AP program at Bishop Reding Catholic Secondary School, who anticipates following a computer science track in university.

Mahmoud Al-Izzi is a junior student at St. Francis Xavier Catholic Secondary School. Aside from his academic achievements in mathematics and science courses, he has participated in Medlife Bites for a Bigger Cause campaign to aid in diminishing the world hunger crisis. His ambition remains paramount in the health sciences field.

Monica Elzawy is currently an undergraduate student studying Biomedical Science at the University of Guelph. She has a continuous desire to learn and a passion for facilitating knowledge transfer in academia.

Ahmed Al-Izzi is a dental student at the University College Cork Faculty of Dentistry. He is constantly eager to keep himself updated on advancements in the healthcare field through attending continuing medical education courses, participating in research activities, and engaging in community services.

Abanoub Aziz Rizk is a medical student at the University of Ottawa Faculty of Medicine. He has a great interest in medical education and wishes to instill love for learning amongst others through research and community initiatives. 